\title{
COMO NÓS ÉRAMOS. NASCITUROS E FETOS NA HISTÓRIA: ENTRE IMAGENS E IMAGINÁRIO*
}

\section{The way we were. The unborn and the fetus in History: between the images and the imaginary}

\author{
Claudia Pancino**
}

\begin{abstract}
RESUMO
A partir do século XVI, encontram-se nos textos médicos imagens de nascituros ou fetos. Observadas em seqüência cronológica, aquelas ilustrações atestam a passagem de uma idéia "afetiva" da formação da vida no ventre materno a uma imagem científica e "verossímil". Por muito tempo, depois dos estudos de Leonardo sobre o feto, continuam sendo desenhados fetos fantásticos, uma vez que o único "estudo" possível sobre o feto era aquele de um cadáver. Estudar a morte para conhecer a vida esteve, durante séculos, em contradição com a mentalidade difundida. Realmente, até o século XVIII o olhar médico se deteve aquém do ventre grávido, respeitando o segredo que envolvia a gestação. Somente no século XIX o pensamento científico separará o nascituro da mãe: os fetos começam a ser desenhados em um fundo branco ao invés de dentro do útero. $\mathrm{O}$ habitat não é mais a simbiose materna, mas um livro ou um atlas, onde o feto começará a ser pensado quase como uma espécie em si, e não mais como um bebê que é esperado.
\end{abstract}

Palavras-chave: feto; ilustração científica; iconografia anatômica.

\footnotetext{
* Artigo traduzido por Elizabete Berberi.

${ }^{* *}$ Professora da Universidade de Bolonha
} 


\begin{abstract}
Since the sixteenth century pictures of unborn babies or of fetuses have been found in medical texts. If analyzed in a chronological sequence, these pictures testify a shift from an "affective" view of the shaping of life in the womb to a scientific "realistic" one. Long after Leonardo's portrayed studies of fetuses were still fanciful; this was due to the fact that the only possible "study" on fetuses could be made on corpses. For many centuries, studying death in order to learn about life was in deep contrast with the mentality of the time. Until the seventeenth century medical observation stopped short of the pregnant womb, thus honoring the secrecy that surrounded gestation. It was only in the eighteenth century that scientific thinking would separate the unborn child from the mother: for the first time fetuses are pictured against a white background rather than inside the womb. An unborn baby's habitat is no more a maternal symbiosis but a book or an atlas where the fetus is presented as a species per se instead of an expected child.
\end{abstract}

Key words: fetus; scientific illustration; anatomic iconography.

A partir do século XVI, nos textos médicos, sobretudo nos de obstetrícia, encontram-se seqüências de imagens que representam o nascituro, ou o feto. Vistas hoje em ordem cronológica, as representações deixam perceber a passagem de uma idéia "afetiva" da formação da vida no ventre materno para uma imagem científica e "verossímil": mais ainda, delas emerge a construção da imagem social do feto como produto histórico e cultural, da qual a iconografia anatômica foi um importante vetor.

Nas páginas que se seguem, me proponho a apresentar algumas passagens de uma pesquisa mais ampla que diz respeito exatamente à análise das imagens que - principalmente entre o século XVI e o XIX - representam o nascituro, utilizando algumas vezes também imagens mais antigas, outras vezes imagens mais recentes, ou muito recentes, como por exemplo, as dos quadrinhos ou do diagnóstico médico por imagem (imaging). Tudo isso tanto para conhecer o "imaginário sobre a vida pré-natal" que influenciou as representações iconográficas, quanto para seguir a hipótese de que as próprias imagens possam, por sua vez, ter contribuído para a construção da concepção moderna da criança em formação.

Quero, porém, deixar claro que não pretendo falar aqui de aborto, reivindicando o direito de falar dos fetos e nascituros pensando-os apenas como futuros seres humanos, crianças que virão ao mundo e por isso são 
esperadas, já que é disso que falam as nossas fontes e é esse o objeto de interesse da minha pesquisa.

Por outro lado, faço questão de esclarecer que também não compartilho da mística da espera, freqüentemente tão enaltecida, considerando que os sentimentos experimentados por uma mulher que sente a formação de uma vida em seu ventre podem ser muito diferentes e contrastantes, tanto hoje como no passado: alegria e temor, esperança e medo de morrer, satisfação e ansiedade, etc.

A curiosidade que abriu caminho ao que se transformou em um projeto de pesquisa, e depois em um livro, tomou impulso no confronto entre os estudos de Leonardo da Vinci sobre o feto e as sucessivas gravuras quinhentistas que ilustram os primeiros manuais de obstetrícia prática. ${ }^{1}$ Os desenhos daqueles libretos de obstetrícia do século XVI são absolutamente fantásticos e ignoram completamente a verossimilhança dos fetos que Leonardo havia desenhado antes daquelas ilustrações. Por que os ilustradores continuaram a desenhar nascituros inverossímeis? A possibilidade de que os gravadores não conhecessem a obra do grande gênio não me pareceu uma resposta satisfatória.

\section{A ilustração pré-cientifica}

Aproximadamente cinqüenta anos depois da publicação do $D e$ humani corporis fabrica de Andrea Vesalio, ou seja, em 1596, Scipione Mercurio, médico romano, "introduzia" a sua obra de obstetrícia prática em língua vulgar, La comare, com o desenho de um nu feminino. ${ }^{2}$ Trata-se de uma deliciosa jovem em pé, em pose relaxada, com cabelos ondulados

1 Cf. PANCINO, C.; D’YVOIRE, J. Formato nel segreto: nascituri e feti fra immagini e immaginario dal XVI al XXI secolo. Roma: Carocci, 2006. Neste artigo se faz referência sobretudo à parte da pesquisa a cargo desta autora e da qual trata a primeira parte do volume. Na segunda parte, Jean d'Yvoire desenvolve a questão da representação do feto na época contemporânea, da imaging médica à literatura, seguindo "o auferimento de uma realidade objetiva" ao feto, bem antes do nascimento.

2 MERCURIO, S. La comare o raccoglitrice. Venezia: appresso G. B. Cioti, 1596. As próximas citações desta obra serão retiradas da edição veronesa de 1654. Sobre La comare e a figura de Scipion Mercurio, cf. PACINO, C. Scipion Mercurio: il pensiero e la carriera di un medico nella prima Età moderna. In: BIONDI, A. (a cura di). Modernità: definizioni ed esercizi. Quaderni di Discipline Storiche, 12. Bologna: Clueb, p. 248 et seq. 1998. 
- aparentemente não escuros - presos na nuca, e depois descendo pelos ombros ligeiramente caídos. O corpo bem robusto, ou melhor, gordinho, reproduz os cânones da estética renascentista: seios pequenos e firmes, coxas fortes, mas arredondadas, mãos e pés pequenos, delicados e roliços a um só tempo. ${ }^{3}$ As mãos cobrem pudicamente os seios, que se deixam entreverem pequenos e firmes, e ao mesmo tempo indicam o ventre aberto no qual pousa o olhar concentrado da protagonista. Como uma espécie de cortina, o tecido da pele ${ }^{4}$ se abre, deixando entrever um minúsculo bebê encolhido que parece olhar para fora com os braços tesos e cruzados. ${ }^{5}$

Um detalhe interessante da imagem é a pequena meada de "fios" que pende abaixo do corte, e que parecem ser provenientes de uma espiral que seccionada deixa ver o bebê. A confirmação vem de uma outra gravura do mesmo texto na qual essa mesma jovem, em outra pose, mostra no meio da barriga uma espiral: isto não é de espantar, dada a antiga difusão do símbolo da espiral para representar o interior do corpo humano, ou o corpo humano em si. ${ }^{6}$ Essa jovem poderíamos chamar de mãe-espiral.

Podemos acrescentar que, no caso da mãe-espiral, a referência é a concepção medieval de embriologia ${ }^{7}$ segundo a relação microcosmomacrocosmo. O útero como "imagem do universo", microcosmo que reproduz o grande mundo, é circular nessas representações e é apresentado como concêntrico à imagem e semelhança do mundo: o feto está no útero como o homem está no universo.

É importante lembrar que o texto com a imagem acima descrita teve um número considerável de edições, e algumas traduções importantes, ou seja, teve certa difusão e foi reeditado até o início do século XVIII.

3 Sobre os cânones renascentistas de beleza feminina, cf. GRIECO, S. M. Corpo, aspetto, sessualità, in: DUBY, G.; PERROT, M. (Orgs.). Storia delle donne: dal Rinasciemtno all'età moderna, p. 53-99; PANCINO, C. Soffrire per bem comparire: corpo e bellezza, natura e cura. In: BELFANI, M.; Gusberti, F. (Orgs.). Annali della Storia d'Italia, 19, Moda e società, Torino: Einaudi, 2003. p. 5-42.

4 Sobre a pele como uma cortina, cf. GÉLIS, J. La spoglia dell'uomo. In: Corpi, p. 102-120; e BOHDE, D. Skin and the search for the interior: the representation of flayng in the art and anatomy of the Cinquecento, Bodily Extremities, p. 10-47.

5 Cf. também a bela imagem do feto no útero - Female figure, de Jost Negker (Augsburg 1538), - e as de Jean Ruelle (Paris 1540), citadas por CARLINO, A. Paper bodies: a catalogue of anatomical fugitive sheets, 1538-1687. London: Wellcome Institute for the History of Medicine, 1999, respectivamente nas p. $122-123$ e 164 . Corpi, p. 55-68.

6 ZANCA, A. Schemi corporei umani medievali e d'Età moderna: loro origini lontane,

7 Cf. NARDI, G. M. Problemi d'embriologia umana antica e medioevale. Firenze: Sansoni, 1938; MARTORELLI VICO, R. Medicina e filosofia: per una storia dell'embriologia medievale nel XIII e XIV secolo. Milano: Guerini, 2002. 
Percorrendo um caminho contrário àquele de 1596, quando veio à luz a Comare com o bebê olhando para fora de dentro da barriga de sua mãe, vamos nos deter em outros seres humanos desenhados antes de nascerem como os homúnculos de tantos debates sobre a teoria da geração ${ }^{8}$ - ou seja, nos remetemos às séries de desenhos de fetos que aparecem nas diversas edições de dois dos mais difundidos manuais de obstetrícia prática do século XVI: os de Jacob Rueff e de Eucherius Rosslin (ou Rhodion). ${ }^{9}$ Tais autores, ambos médicos, um suíço e o outro alemão, tinham publicado um texto fácil em língua vulgar, para que dele pudessem tirar proveito as mulheres que assistiam os partos. O aparato iconográfico, como nós chamaríamos hoje, parece ter tido nessas obras precisamente o objetivo de confiar à imagem a explicação do texto, não somente pela descrição do parto natural, mas também no que diz respeito às posições patológicas ou "não-naturais" do feto na hora do nascimento. ${ }^{10}$ Nas mais de quarenta edições somadas desses dois textos nos diversos países europeus, as gravuras se repetem com poucas modificações significativas. $\mathrm{O}$ feto aparece sempre representado como um homenzinho em miniatura que se move em um recipiente em forma de pêra invertida, e assume, nas diversas imagens, várias posições. $\mathrm{O}$ que muda nas edições com o passar dos anos é o desenho, mais ou menos simples do útero-pêra, e o estereótipo da representação da "criatura". ${ }^{11}$

Em uma antiga edição do Rosengarden - contração do título original

8 Sobre o tema, cf. pelo menos o já clássico ROGER, J. Les sciences de la vie dans la pensée française du XVIII siècle: la génération des animaux de Descartes à l'Encyclopédie. Paris: Colin, 1963. (última ed. Paris, Albin Michel, 1993)

9 ROSSLIN, E. De partu hominis, et quae circa ipsum accidunt, adeoque de parturientum \& infantium morbis atque cura, Frankfurt, apud HAERED, Christ. Egenolphi, 1563; RUEFF, J. De conceptu et generatione hominis, Frankfurt ad Moenum, apud Georgium Corunium, 1580, [ed. original em alemão. c.1535]. A primeira edição de Rosslin, de 1513, em alemão, tem como título Der swangern Frauwen und Hebamen Rosengarten. Falei rapidamente sobre isso em PANCINO, C. Il bambino e l'acqua sporca: Storia dell'assistenza al parto dalle mammane alle ostetriche (secoli XVI-XIX). Milano: Angeli, 1984, p. 25-27, e em COSMACINI, G. (Org.). L'arte dei parti nel Cinquecento. In: Storia dell'ostetricia, 1, Milano: Intramed, 1989. p. 15-23. O texto de Rosslin teve entre o século XVI e o século XVII inúmeras reedições e traduções nas principais línguas européias, e a partir da década de 70 do século XIX foi objeto de vários estudos e reedições, em latim e em alemão, sobretudo na Alemanha.

10 A questão da relação entre texto e ilustração nos textos científicos é, na verdade, um tanto complexa. Cf. KEMP, M. Templi del corpo e templi del cosmo: visione e vusualizzazione nella rivoluzione vesaliana e copernicana. In: Immagine e verità: per uma storia dei rapporti fra arte e scienza. Milão: II Saggiatore, 1999. p. 67-103, e do mesmo, Il segno della verità; visione e sapere in alcune illustrazioni anatomiche del Rinascimento e del Settecento, op. cit., p. 199-229.

11 Sobre as diversas edições desses textos e suas diversas ilustrações, cf. LEROY, F. $\mathrm{Hi}$ stoire de naître: de l'enfantement primitif à l'accouchement médicalisé. Bruxelles: De Boeck, 2002. p. 123-129. 
da primeira edição de Rosslin, como é mais conhecido - os que não podem ser definidos senão como "crianças" encontram-se cada um em um recipiente que se parece com uma ampola de vidro de ponta-cabeça, quase uma lâmpada, onde aparentam nadar com leveza. Ou ainda, as poses fazem pensar em uma foto de um corpo em movimento: um está de costas escorregando para baixo e abre os braços, enquanto os cachinhos nem se desmancham; o outro, com os olhos bem abertos, parece saltar com os joelhos afastados e os pés unidos, em direção ao colo do útero-lâmpada. Um terceiro parece mergulhar de barriga na água, olhos abertos e cachos penteados; um outro ajoelhado e com o olhar voltado para a "saída", parece estar pensativo. As feições desses homúnculos não são exatamente aquelas de um recémnascido, mas sim de uma criança - um pequeno homem de pescoço taurino, atarracado. ${ }^{12}$ Em duas dessas imagens é evidente o sexo masculino. Pode-se mesmo dizer que nenhuma das imagens examinadas representa pequenos corpos femininos (com uma única exceção, como veremos). Uma característica dessas imagens, recorrente também nas outras das várias edições, é o amplo espaço de movimento do qual usufruíam aqueles bebês-lâmpadas. Em cada "invólucro" caberia pelo menos mais um.

Em outras edições, o traço mais grosseiro da gravura desvaloriza a imagem delicada do feto, descrita anteriormente, em favor de uma exemplificação da representação fetal sem objetivos estéticos, ainda que nesse texto não faltem também, mesmo que um tanto fantásticas, outras imagens desenhadas com maior capricho. É o caso de um feto - dessa vez vale a pena chamá-lo desse modo, pois se aproxima de representações mais modernas - isoladas de qualquer contexto materno, suspenso no fundo branco da página na "clássica" posição encolhida, com as mãos cruzadas e a cabeça inclinada sobre os joelhos. Uma outra imagem da mesma edição, que faz parte da série de partos de gêmeos, apresenta os dois irmãozinhos - evidentemente de sexo masculino - desenhados com traço grosseiro e feições um pouco duras, em pé e ternamente abraçados, isto é, cada um apoiando o braço no ombro do outro, e simetricamente com os pés um na frente do outro, olhos nos olhos (posição notadamente podálica). O mesmo

12 Loris Premuda, em suas páginas dedicadas às representações anatômicas do feto na história da medicina, interpreta as representações dos fetos-homenzinhos, com o pouco interesse pela infância por parte da sociedade naquele momento, levantando assim, hipóteses que, uma década mais tarde, seriam a base das famosas teorias de Philippe Ariès sobre o sentimento da infância. Cf. PREMUDA, L. Storia dell'iconografia anatomica. Saronno: Ciba, 1993 (1957). p. 28. 
tema aparece em diferentes versões em várias edições. Por exemplo, em uma outra edição os gêmeos, sempre abraçados do mesmo modo, aparecem desta vez naturalmente de ponta-cabeça, em um estado que se poderia dizer mais "cotidiano" (se se tratasse de bebês de verdade), enquanto o saco no qual se encontram aparece aqui mais escuro e sombrio, não transparente. O útero, invertido na ilustração, não é mais uma lâmpada clara, mas um saco no qual três camadas de tecido foram rasgadas para se poder ver os bebês. A representação do útero, muito espaçoso para os seus habitantes - tem uma intenção de verossimilhança, mas com duas excrescências em forma de "roseta" onde o oval se estreita para assumir a forma de pêra. Esses gêmeos não são muito diferentes daqueles mais tardios, do texto de Scipione Mercurio do qual falamos no início, e dos quais estão separados por cerca de cinqüenta anos. No útero, de novo em posição natural - isto é, com a boca para baixo - de um tecido encorpado, no qual é visível um profundo corte de contorno periforme. Mas não linear, abre-se uma cortina cujas bordas se transformam em: uma moldura quadrada no fundo da qual estão dois minúsculos gemeozinhos sempre abraçados e em pé; o olhar apagado representado apenas pelo contorno dos olhos sem pupilas; cabelos bem desenhados, muito espaço vazio em volta. ${ }^{13}$

Seria possível continuar com semelhantes descrições, mas é um passo em direção oposta no tempo que introduz um elemento de ruptura. Trata-se precisamente dos fetos de Leonardo da Vinci.

Os estudos desse artista sobre o feto remontam aos anos de 15101512: são desenhos de úteros e fetos nos diversos estágios da gestação, figuras absolutamente diferentes daquelas das quais se falou até agora, muito mais "verossímeis". Verossímil a posição do feto no útero, o espaço que este ocupa entre as paredes uterinas e, em suma, até o seu aspecto. Isso porque os fetos representados se parecem de fato com um bebê de verdade, não são homúnculos. De fato, sabe-se que Leonardo teve à sua disposição, para os seus desenhos, um feto humano com cerca de sete meses, e que suas informações derivavam da observação anatômica direta. ${ }^{14}$ Os fetos de

13 Sobre a embriologia de Leonardo, cf. ao menos LAURENZA, D. La ricerca dell'armonia: rappresentazioni anatomiche nel Rinascimento. Firenze: Olschki, 2003; CIANCHI, C. Leonardo: Anatomia. Firenze: Giunti, 1997. p. 40-43, 60-61; KEMP, M. Templi del corpo e templi del cosmo..., p. 71-73.

14 Leonardo escreveu: "O filhinho está no útero circundado pela água porque as coisas sujeitas à gravidade pesam menos na água do que no ar, e menos ainda quando a água é viscosa e espessa. E também esta água distribui o seu peso e o da criatura, no fundo e nos lados do útero." (CIANCHI, C. Leonardo, p. 41-42) 
Leonardo são de uma beleza rara e ao mesmo tempo terrível porque muito semelhantes ao real, diferentemente dos descritos anteriormente, fantásticos e poéticos, absolutamente inverossímeis. ${ }^{15}$

Já se disse que ainda em 1596, mas não somente nesse período, como por exemplo, em todas as edições sucessivas da Comare, a iconografia do feto era aquela imaginária, tão distante dos "fetos verdadeiros" de Leonardo. Por que se continua a representar o feto no útero como na Idade Média? De fato, é dessa época que provêm os homúnculos imaginados e desenhados nos textos do século XVI.

Um desenho impressionante, colorido, de um manuscrito medieval do Gynaekeia de Muscione ${ }^{16}$ mostra, para ilustrar o parto podálico, um homúnculo, miniatura de um homem adulto, com uma vasta cabeleira negra, em pose de ginástica: corpo ereto, de ponta-cabeça bem entendido, braços simétricos acima da cabeça, pernas levemente afastadas, pé direito à frente e o esquerdo de lado, olhar fixo em direção ao público. O útero, em forma de cabeça de gato com duas pequenas orelhas pontudas, acomoda-o confortavelmente. ${ }^{17}$ Outras representações daquele tempo não se distanciam muito do modelo. Esse tipo de homúnculo será proposto outras vezes, com as devidas melhorias e influências de estilo, nos sucessivos manuais e tratados de obstetrícia prática, a partir daqueles que chamamos fetos-lâmpadas.

A resposta para essa questão colocada acima poderia ser que, para "saber" que no ventre de uma mulher grávida existe alguma coisa de semelhante ao feto de Leonardo, e não mais um homenzinho em pose de dança, é preciso passar pelo reconhecimento do horror da morte, e aceitar que alguém

15 Kemp escreve a propósito do Studio del feto e dell'utero de Leonardo: “A peremptória linguagem objetiva por meio da qual os desenhos se expressam não é, contudo, tal a encorajar quem os observa a estar plenamente consciente dos limites e armadilhas da representação naturalista" (Templi del corpo e templi del cosmo..., p. 73).

16 Trata-se de um manuscrito do século IX, conservado na Bibliothèque Royale de Belgique, do qual foram tomadas as imagens coloridas reproduzidas por LEROY, F. Histoire de naître.... Para o texto de Muscione/Moschione/Mustio, cf. SEGOLONI, M. P. (Org.). Gynaeciorum Muscionis concordantiae: accedunt: indices frequentiae, index inversus, index formarum similium, onomasticon, index numerorum, Hildesheim: Olms-Weidmann, 1993. Do Gynaekeia existe também uma tradução italiana, La Gynaecia di Muscione: manuale per le ostetriche e le mamme del 6. sec. d.C., tradução italiana e notas com texto latino tirado dos códices e vasto glossário aos cuidados de Radicchi, Pisa: Giardini, 1970. A obra foi recentemente reeditada em alemão, juntamente com o texto de Rosslin: Gynaecia Mustionis, der Hebammenkatechismus des Mastio (deustsch um lateinisch) \& Eucharius Rösslin “Rosengarten”, Frankfurt am Main, Haag und Herchen, 1997.

17 A imagem foi extraída de LEROY, F. Histoire de naître ...,. p. 112. 
(por nós?) afunde uma faca em um cadáver. ${ }^{18}$ É somente a prática da anatomia que permite a Leonardo conhecer o aspecto do feto. É, portanto, do contato com a morte, em sua violenta relação com a geração e o nascimento, que se vale o conhecimento científico do que ocorre no interior do corpo feminino durante o longo período da gestação, e é sempre o olhar anatômico a descobrir, de modo desagradável, como nós éramos antes de vir ao mundo.

É provavelmente esse choque inevitável entre os universos do nascimento e da morte - e da sua dessacralização anatômica ${ }^{19}$ - que faz com que no território da geração o pensamento científico e o que se poderia definir como o imaginário pré-científico possa conviver por muito tempo.

Seria possível levantar a hipótese de que a anatomia fosse como de fato era uma experiência de poucos, longe do conhecimento e da experiência dos médicos práticos, autores dos livros nos quais aparecem as imagens fantásticas. No caso do médico Scipione Mercurio, sabe-se que ele teve oportunidade de assistir aulas e demonstrações anatômicas, que lhe serviram como fonte de conhecimento e maravilha inauditos ${ }^{20}$; teve também oportunidade, com o grupo de seu mestre Giulio Cesare Aranzi, de estar presente a uma cesariana em uma mulher morta, e de poder observar "o lugar natural da criatura humana no ventre materno"21.

Tinha realmente visto. Seria possível ainda objetar que nos textos de medicina prática do século XVI as imagens pudessem não corresponder às descrições do texto, ou seja, ao que o autor realmente expressou, quer dizer, que as ilustrações não fossem discutidas previamente entre $o$ autor e $o$ editor. $O$ exemplo de Scipione Mercurio demonstra novamente o contrário: por um lado

18 Foi deixada de lado a análise do público para o qual as obras eram destinadas. Confrontando os esfolados de Vesalio com o "estilo cruamente direto" di Wächtlin, Kemp introduz a variável "público", levantando a hipótese de que sendo as duas obras, de Vesalio e de Wächtlin, uma em latim e a outra em vulgar, os autores consideravam que eram destinadas a um público também com exigências "visuais" diferentes (KEMP, M. Templi del corpo, templi del cosmo, ..., p. 74-75). Há que se levar em consideração que as obras de Rueff, Rösslin e Scipione foram escritas em vulgar e não "no latim dos doutores".

19 Cf. CARLINO, A. La fabbrica del corpo, op cit.

20 MERCURIO, S. De gli errori popolari d'Italia, libri sette. Veneza. In: CIOTTI, G. B. 1603, p. 41. Sobre Mercurio e os Errori, cf. PANCINO, C. I medicamenti sono di tre sorti: magia, scienza e religone ne "Gli errori popolari d'Italia" di Scipione Mercurio. In: PROSPERI, A. (Org.). Il piacere del testo: saggi e studi per Albano Biondi. Roma: Bulzoni, 2001, v. I, p. 385-421. Uma análise interessante da "cientificidade" dos escritos de obstetrícia de Scipione Mercurio está em CURATULO, E. L'arte di Juno in Roma. Roma: [s.n.], 1901, p. 151-155.

21 MERCURIO, S. La comare, ..., p. 41. Aranzi, na edição de 1587, data de 1565 um episódio de dissecação que parece ser o mesmo descrito por Mercurio. Sobre o uso do termo "feto" e o correspondente nas várias línguas vulgares, Il corpo della donna come luogo pubblico: sull'abuso del concetto di vita. Turim: Bollati Boringhieri, 1994. De modo geral, sobre a concepção do feto, cf. DUDEN, B.; VEIT, S. (Org.). Geschichte des Ungeborenen: zur Erfahrungs-und Wissenschaftgeschichte der Schwangerschaft, XVII-XX Jahrhundert. Göttingen: Vandenhoeck \& Ruprecht, 2002. 
há testemunhos do relacionamento e da amizade com o editor, já que o médico fala em seus escritos dos encontros com o seu "impressor". E, além disso, em uma passagem do Comare ele critica o texto e as imagens da edição de Rueff que ele conhecia (não sabemos qual edição), demonstrando assim considerar um autor responsável pelas imagens que ilustravam os seus escritos. ${ }^{22}$ Além disso, no seu Comare não hesita em introduzir algumas vezes ilustrações que acompanham as descrições, como faz a propósito do "lugar natural" do útero:

Se faz necessário que para maior clareza se coloque aqui embaixo uma figura, de como está o útero no corpo das mulheres não grávidas, podendose assim ver o lugar natural da criatura nesse útero $[\ldots]^{23}$

A ele, Mercurio, cabe, portanto a responsabilidade das imagens do seu texto, ainda que não estejam de acordo com a sua experiência anatômica. Aquilo que descreve depois da dissecação com Aranzi, mesmo que mais parecido com as imagens evocadas pelos fetos de Leonardo do que com as do seu próprio livro, aparece por isso mesmo mais "moderno" do que as ilustrações, embora já estereotipado. ${ }^{24}$

22 Sobre a relação entre autores e ilustradores, cf. ainda KEMP, M. Il segno della verità..., op cit.

23 Ibid., p. 16.

[...] tive grande prazer em ver pessoalmente o lugar natural da criatura humana no ventre materno, o qual é da seguinte forma. Tem ela a cabeça na parte superior do útero onde este é maior, os braços dobrados de tal modo, que os cotovelos ficam ao lado dos quadris: as palmas das mãos estão apoiadas nos joelhos: as pernas afastadas, e cruzadas, voltando-se as plantas dos pés para as nádegas: os olhos pousados sobre os joelhos, tocando com as bochechas o exterior das mãos, e o nariz fica entre os joelhos. A criatura assim recolhida forma de si mesma uma figura circular, e essa figura ocorre não só porque é assim desejada pela natureza, como a mais perfeita dentre todas as figuras matemáticas, mas também porque em tal figura a criatura possa mover-se com desenvoltura, e sem incômodo para a mãe a cada mudança de posição: por isso é muito apropriada a figura circular, e qualquer outra teria sido inútil. Aqui deve-se advertir, que estando a criatura neste lugar, tem o rosto em perspectiva em relação ao ventre da mãe, e não em relação às costas, como sonhou Giacomo Rueffo em seu livro segundo da geração e concepção humana [...], onde mostra isto em um desenho, mas eu penso que este homem nunca viu Anatomia, nem se certificou na prática sobre este lugar natural do homem: mas tendo lido uma obra de Eucherio Rodione, médico, que foi primeiramente escrita em língua alemã, e depois traduzida em latim por Cristiano Eginolso, fez dela como se fosse sua, acrescentando um latim melhorado, isto não se pode negar acrescentando as suas figuras alguns aperfeiçoamentos. (MERCURIO, op. cit., p. 14-15, grifo meu).

"Deve-se ter presente que em uma dissecação, a qual de modo inevitável comporta uma certa confusão, o 'ver' não seria prontamente traduzido pelo 'conhecer'” (KEMP, M. Templi del corpo, templi del cosmo, op. cit, p. 75). A descrição Della posizione del feto in utero na terceira edição do De humano foetu de Aranzi está nas p. 32-35 da edição italiana (e é muito mais precisa e detalhada do que a presente na primeira edição). Desta não se afasta muito Scipione Mercurio. 
A distância entre o que foi visto e o que foi reproduzido através da imagem, o fato de que somente uma imagem anatômica passada pelo filtro do imaginário seja representada nas gravuras que ilustram o texto, talvez possa ser explicado pela constatação de que os olhos vêem o que querem ver, ou melhor, o que podem e o que suportam ver: "Permanece inalterada, hoje como naquela época, a tendência daqueles que investigam algo complexo e indecifrável, como o corpo dissecado, de encontrar aquilo que esperam encontrar". ${ }^{25}$

$\mathrm{Na}$ escuridão do ventre materno, e na fantasia da humanidade na mentalidade coletiva - as "criaturas" no útero são mais comumente "crianças na lâmpada" do que fetos reconhecidos nos corpos mortos de suas mães e, na maioria das vezes, cadáveres eles também. Se a partir dos anos 60, do século XX, vemos "verdadeiras fotografias" de fetos nos vários estágios da gravidez, e hoje até os livros para crianças apresentam imagens "verossímeis" de fetos coloridos dentro de seu saco amniótico, é porque a partir de Leonardo o conhecimento, ou melhor, especificamente esse tipo de conhecimento, que é o da ciência médica, foi baseado na investigação anatômica, até o surgimento das ecografias e do diagnóstico médico por imagem. De fato, somente na segunda metade do século XX essa investigação valeu-se da fotografia, até não muito tempo atrás, de fotografias de fetos mortos durante a gravidez. ${ }^{26}$

Aquelas imagens modernas, propostas como verdadeiras ou verossímeis, de alguém que estaria para nascer, contêm o profundo engano de serem imagens de mortos, onde a morte é negada e escondida graças a uma série de artifícios, e o que há de "verdadeiro" é manipulado com outros tantos artifícios. As imagens de Lennart Nilsson - que a partir de um número da revista Life de 1965 foram inseridas em todo o tipo de publicação de divulgação, desde manuais de preparação para o parto até os textos escolares $^{27}$ - são coloridas graças às lâmpadas do fotógrafo, e os fetos são rosados, sem pregas, "limpíssimos". Em todas as representações do parto, todo tipo de líquido ou substância que suja (ou protege) o bebê está ausente.

25 KEMP, Il mio bell'ingenio, op. cit., p. 85. Para Barbara Duden, simplesmente a imagem do feto, nos textos de anatomia, permaneceu por muito tempo um símbolo (DUDEN, B. Il corpo della donna, op. cit., p. 41). É extraordinária para a época a prancha de um feto no útero, de Girolamo Fabrici d'Acquapendente (1600). Não é um homúnculo nem um anjo barroco que está representado, mas um feto "de verdade".

26 Cf., nesse volume, o ensaio de Jean d'Yvoire, L'irruzione del feto nel mondo dell 'immagine e dell'immaginario (ovvero lo svelamento del segreto?).

27 Ibid., p. 145-152. 
Retornando a Scipione Mercurio, podemos recordar que esse autor que descreve as membranas uterinas ${ }^{28}$ tinha visto o saco amniótico, mas, por exemplo, não desenha os gêmeos em dois sacos, mas abraçados, como ainda gostamos de vê-los.

No território da geração e do nascimento, a relação entre vida e morte é estreita e ao mesmo tempo ambígua. Não só porque até pouco tempo atrás dar a vida significava para as mulheres correr o risco de morrer - e disso se tinha consciência nas sociedades do passado - mas também porque os conhecimentos e progressos científicos no campo obstétrico foram obtidos "graças" ao estudo da morte na materialidade dos corpos mortos. Não apenas a observação anatômica foi o laboratório para o conhecimento da fisiologia e da patologia da gestação e do parto, mas também operações de salvamento como a cesariana têm uma história truculenta. Se no século XIX começaram a salvar as mães e os filhos com o corte cesáreo, isso aconteceu também porque Emanuele Cangiamila, teólogo palermitano, armado com um bisturi, tinha, no início do século XVIII, cortado os cadáveres de todas as mulheres mortas grávidas - ou supostamente grávidas - ao seu alcance, para batizar os fetos, sem que nenhum, aparentemente, sobrevivesse a essa ação pastoral. ${ }^{29} \mathrm{O}$ livro que fala de tal iniciativa tem um título inquietante: Embriologia sacra. O ímpeto pastoral de Cangiamila, porém, teria suscitado a curiosidade de cirurgiões, que estariam por sua vez preocupados em transformar aquela operação em uma intervenção de salvamento.

Tudo aquilo que se vinha a saber "graças" à anatomia não podia agradar a uma mulher que estava prestes a ser mãe; provavelmente durante longo tempo aquele tipo de informação não podia ter nada a ver com as transformações do seu corpo nem com os seus sentimentos. Por esse motivo, diversos conhecimentos e informações não podiam senão sedimentar-se em

28 MERCURIO, S. La comare, op. cit., p. 15.

29 CANGIAMILA, F. E. Embriologia sacra, overo dell'uffizio de'sacerdoti, medici, e superiori, circa l'eterna salute de 'bambini racchiusi nell'utero. Palermo: Francesco Valenza, 1745. Também trata difusamente do tema N. M. Filipini, La nascita straordinaria: tra madre e figlio la rivoluzione del taglio cesareo, sec. XVIII-XIX. Milano: Angeli, 1995. p. 59-101. A obra de Cangiamila foi recentemente reeditada, com introdução de R. Forleo, Roma, CIC Edizioni Internazionali, 2001. Romano Forleo, ginecologista católico, citando algumas linhas de C. sobre o desenvolvimento embrionário, que começam com "se estes animaizinhos fossem homenzinhos bem formados [...] não teriam outra coisa a fazer dentro do útero a não ser crescer", comenta: "não é lícito sorrir", "estamos em pleno desenvolvimento da medicina científica com visão tipicamente materialista, à qual a Igreja reage, como nos tempos de Cangiamila, com o chamado aos princípios éticos universais, talvez muito encobertos por filosofias espiritualistas que não perderam o vigor com o desenvolvimento do conhecimento" (CANGIAMILA, op. cit.). 
forma de pensamentos que permaneciam separados e paralelos: em uma mesma sociedade, em um mesmo segmento, quem sabe em uma mesma pessoa.

Que as futuras mães não aceitassem aquele tipo de contato entre as diversas concepções do nascimento é confirmado pelas dificuldades que as primeiras parteiras habilitadas encontraram, na Lombardia de Maria Tereza d'Austria, para inserir-se no "mundo do trabalho". As mulheres não as queriam por vários motivos, não por último pelo fato de que nos seus estudos as "parteiras habilitadas" haviam assistido a aulas de anatomia. Este foi o caso, por exemplo, de uma parteira que em 1768 teve recusado o reconhecimento do seu trabalho pelas mulheres da sua comunidade, que davam como justificativa o fato de sentirem "nojo" diante da parteira Angela Maria Caima, que tinha assistido a "demonstrações anatômicas no tempo da escola" ${ }^{30}$.

Exemplos da convivência de formas diversas de pensamento em uma mesma comunidade não faltam. Um deles pode ser aquele veneziano. Está documentada na cidade, nos arquivos paroquiais do século XVIII, a presença de "registros de abortos", junto àqueles de batismo, matrimônio e morte. De fato, às vezes se batizavam os frutos de gestações interrompidas, na eventualidade que pudessem ter uma alma. Isso mostra que qualquer um, médicos e parteiras em primeiro lugar, tinha conhecimento do fato de que durante a gestação não havia homenzinhos dançantes no ventre das mulheres, mas bebês em formação que, vez por outra, acontecia de observar. ${ }^{31}$ No lado oposto dessa moeda, as tradições populares transmitem uma antiga crença, que se transformou num ditado no momento em que foi recolhida pelos folcloristas oitocentistas, mas que, todavia, espelha um modo de pensar específico. Então, se dizia que a criança se formava: "em sangue três meses, em ossos três meses, em carne três meses" 32 . Os nove meses da gestação eram assim subdivididos em três fases equivalentes: na primeira se formava a matéria-prima sanguinolenta, na segunda o sistema ósseo, que depois seria completado pela "carne" no último trimestre. Difícil pensar que essa crença realmente não pertencesse a vários segmentos da população.

30 PANCINO, C. Il bambino e l'acqua sporca..., p. 128-131.

31 Em Bolonha, nos autos do tribunal del Torrone, as parteiras peritas falam de uma "bolinha de carne". Cf. PASTORE, A. Il medico in tribunale: La perizia medica nella procedura penale d'antico regime (secoli XVI-XVIII). Bellinzona: Casagrande, 1998. p. 137.

32 Paralelamente à formação do sangue, dos ossos, da "carne", segundo a tradição muda também a posição do feto: três meses está em baixo, três meses vai para cima, e nos últimos três volta para baixo. Cf. BERNONI, D. G. Tradizioni popolari veneziane: Medicina. Veneza: Filippi, 1968 (1878), p. 138. 
De resto, também o pensamento iluminado dos enciclopedistas estará um pouco em dificuldades: serão mostrados, nas pranchas da Encyclopédie, bizarros "manequins" de fetos. Por um lado, o olhar que se pretende científico quer separar a criatura - doravante "feto" - da mãe, e a apresenta com o distanciamento necessário ao conhecimento. Mas se se pensa, por exemplo, na representação do esqueleto do feto, fora do corpo materno, fora dos úterospêra, os enciclopedistas não conseguem fazer o "bebê" ficar de pé. A imagem grotesca proposta pelas pranchas de anatomia é, portanto, a do esqueleto de um homúnculo, com um corpo pequeno e um crânio enorme, em posição ereta, mas porque é sustentado naquela postura tão "humana" por um suporte mecânico. ${ }^{33}$ O feto sem a mãe, sozinho, não consegue ainda manter-se de pé.

As pranchas da Encyclopédie sintetizam um ponto de vista e uma curiosidade científica que foram se desenvolvendo durante o século XVIII. O naturalista de Zurique Johan-Jacob Scheuchzer havia publicado na sua extravagante obra Physica sacra (1731-1733) - um comentário científico naturalista da Bíblia - uma prancha que ilustra o momento em que, no Gênesis, "a mais nobre de todas as Criaturas, o microcosmo e o compêndio de todo este grande Mundo, aparece no Teatro do Mundo". A imagem central representando a criação do homem-Adão está contida em uma macabra moldura "animada" na qual artisticamente se desenvolve o percurso do crescimento do embrião (também, nessa alegoria, isolado da relação com a mãe $)^{34}$ : como onze fotogramas em seqüência, numerados com algarismos romanos, os fetos se sucedem em volta da gravura descrevendo a própria

33 Prancha I, n. 2, fig. 3, 4 e 5, em Récueil de planches sur les sciences, les arts libéraux, et arts méchaniques, avec leur explications. Anatomie, Rist. Anastatica, Paris, Inter-livres, 2001. "Les Fig. 3, 4, 5 , représentent des squelettes de fetus de différens âges" (p. 2). Uma representação muito semelhante aparece já em PAAW, P. De european Traditions of Anatomical Illustration. Oxford: Clarendon Press, 1992.

34 Traduzo da edição francesa, J. J. Scheuchzer, Phisyque sacrée, Amsterdam, 1737, t. I (ed. or. Physica sacra, Augustae Vindelicorum \& Vlmae, 1731-1735, as legendas das pranchas XXIII:

Fig. I. A figura mostra um embrião humano, do tamanho de um grão de anis; Fig. II. Um outro do tamanho de um grão de cevada, com o início do cordão umbilical; Fig. III. Um outro um pouco maior do que o anterior, no qual a cabeça já se distingue do corpo e os membros que começam a se formar parecem pequeninas excrescências; Fig. IV. Um outro do comprimento de um dedo em posição transversal; Fig. V. Um outro no qual os membros estão um pouco mais desenvolvidos mas não aparecem ainda os dedos; Fig. VI. Um outro no qual podem-se ver os dedos; Fig. VII. Um outro, um pouco maior; Fig. VIII. Um esqueleto do tamanho do dedo mindinho, que tem em cada uma das mãos alguns ovinhos; Fig. IX. Um outro, um pouco maior, que tem na mão direita um ovo de mulher fecundado; Fig. X. Um outro do tamanho do dedo indicador, que tem na mão esquerda um ovo fecundado, e aberto; Fig. XI. Um outro esqueleto de feto humano, com cerca de quatro meses, e que, como se fosse enxugar as lágrimas, leva aos olhos, no lugar de um lenço, uma pequena membrana com uma infinidade de vasos sanguíneos (op. cit. p. 31).

Sobre Scheuchzer, cf., FELFE, R. Naturgeschichte als kunstvolle Synthese. Physikotheologie und Bildpraxis bei Johann Jakob Scheuchzer, Scheuchzer. Göttingen: Vandenhoeck \& Ruprecht, 2000. 
formação. Assim Scheuchzer comentava a ilustração: "Os ornamentos que estão em volta desta prancha mostram os diversos estágios do crescimento do ovo do qual sai o homem, segundo a moderna anatomia". ${ }^{35}$

Concluída a investigação sobre a verdade no microcosmo-parvus mundus no seu início, de Aranzi a ciência navega em direção a outros horizontes e outras imagens que, sobretudo a partir da metade do século XVIII, terão objetivos, utilidades, imaginários culturais de referência profundamente diferentes daqueles do renascimento. É exemplar o Embryologie ou Ovologie humaine de Alfonse Armand Velpeau (1834) ${ }^{36}$, que, traduzido para o italiano em $1840^{37}$, fala do embrião como se se tratasse de uma espécie em si, e não de um homem ou de uma mulher no início de sua existência, e os pequeninos fetos de suas tão célebres pranchas - muito utilizadas na didática universitária - começam a se parecer com ratos. ${ }^{38}$

Diante daqueles fetos tão "pensados", de Scheuchzer à Encyclopédie, a Velpeau e tantos outros naqueles anos e nos seguintes, faz falta a "jovem" do Comare, desenhada quando o homem em formação não podia ser imaginado sem a mãe e seu corpo, ou ao menos uma parte do seu corpo (o útero-pêra). E aquelas criancinhas no útero nos textos de Rueff, Rhodion, Mercurio, não deixam de lembrar certas Madonas medievais que, vestidas como a realeza, como também o seu filho Jesus, têm o menino não no braço, mas engastado em uma moldura-oval, dentro do seu próprio corpo.

Todavia, é preciso lembrar do outro lado da moeda, isto é, que nenhuma mulher adulta podia ser pensada senão como a "jovem" da qual falamos, como a Vênus de cera do Specola di Firenze ${ }^{39}$, com um minúsculo

35 SCHEUCHZER, op. cit., p. 30.

36 Embriologie ou ovologie humaine contenant l'histoire descriptive et iconographique de l'auf humain, Bruxelles: H. Dumont Librairie Éditeur, 1834.

37 VELPEAU, A. L. M. Embriologia od ovologia umana contenente la storia descrittiva ed iconografica dell'uovo umano. Pisa: Nistri, 1840.

38 De "imagerie médicale", "imagining medico" a propósito da vida pré-natal, ver Jean d'Yvoire, 2006, na última parte. Do mesmo autor, cf. também Le faetus entre normalitè scientifique et monstruosité littéraire. Imagérie médicale et imaginaire du double, em Jarry: le monstre 1900/Jarry: das Monster 1900, Aachen, Medusa Medias, 2002, p. 33-54.

39 Museu de História Natural, criado no século XVIII, pelo Grão-Duque Pietro Leopoldo di Lorena, em Florença, que contém uma importante coleção de peças de anatomia em cera, entre elas a famosa "Venere Medicea". (N. da T.) 
bebezinho no seu ventre. ${ }^{40} \mathrm{~A}$ célebre boneca florentina, obra de Clemente Susini, que a modelou entre 1781 e 1782, em seu requinte estético - talvez com o objetivo de iludir qualquer aspecto da morte - convida a descobrir os mistérios do corpo feminino. Retirado primeiramente o colar de pérolas, descoberta a parede torácica e abdominal, exibidas as veias e as artérias, iluminadas as pregas intestinais, revela no fim do percurso de descoberta científica aquilo que já se sabia: no pequeno útero de cera, uma criaturinha, exatamente em posição "fetal", com a cabeça para baixo, justifica a sua condição de mulher. ${ }^{41}$ Mulher porque mãe, já que aquele bonequinho não pode existir ainda, senão dentro do útero, existe apenas na simbiose materna.

Imagens muito mais antigas, com os mesmos tons de vermelho, parecem assinalar a secular persistência do tema: na ilustração anatômica do corpo feminino, colorida, do manuscrito Welcome 290, que remonta, segundo os estudiosos, ao século XIII, falta a graça da Vênus do Specola, mas igualmente a mãe - com pernas e braços abertos, mas com os mesmos cabelos soltos da cera florentina - justificava o fato de o filho estar em seu útero, mas ao mesmo tempo testemunhava que nenhuma mulher "observada" profundamente podia separar o seu ser mais "verdadeiro" do fato de ser pensada para procriar. $^{42}$

A crítica observou, tanto a respeito da boneca desmontável quanto a respeito da pequena mulher do manuscrito Welcome 290, que aquilo que estava representado não fazia justiça ao nível do conhecimento anatômico

40 Foge ao tema destas páginas e ao âmbito cronológico aqui considerado a análise dos "fetos" do Specola di Firenze, que, como aqueles da coleção obstétrica de Gian Antonio Galli em Bolonha, estão inseridos em um novo grupo de representações nas quais, sobretudo nas bolonhesas, a finalidade didádica propõe uma nova relação seja com a "tradicional" finalidade científica, seja com a pesquisa estética. Muda profundamente o compromisso com o imaginário do corpo do bebê antes do nascimento pressuposto naquelas representações anatômicas.

41 Sobre a boneca de cera do Specola di Firenze, cf. AZZAROLI, M. L. et al. Pertugi, La Venere scomponibile, "Koss", I, 1984, p. 65-94; POGGESI, M. La collezione ceroplastica del Museo "La Specola". In: Encyclopaedia Anatomica. Una selezione di cere anatomiche, Museo di Storia Naturale dell'Università di Firenze. Köln: Taschen, 2001. p. 6-13; DÜRING, M. L'anatomia del corpo umano. Una collezione unica del tardo XVIII secolo. In: Encyclopaedia Anatomica, ..., p. 30-31; AZZAROLI, M. L. La Specola: il museo zoologico dell'Università di Firenze. Firenze: Olschki, 1975; LANZA, B. (Org.). Le cere anatomiche della Specola. Firenze: Arnaud, 1979; HUBERMANN, D. G. Aprire Venere: nudità, sogno, crudeltà. Torino: Einaudi, 2001. p. 81-98.

42 GETZ, F. M. H. Anatomia del Medioevo, "Koss”, I, 1984, p. 33-46. A ilustração do corpo feminino, do manuscrito Wellcome 290, é reproduzida a partir de uma fotografia da Wellcome Library, na p. 43 . 
da época. ${ }^{43} \mathrm{O}$ caso não é raro no que se refere às ilustrações científicas. Mas a coincidência impressiona: não poderia ser neste caso que o tema, ou seja, o objeto da representação escapasse às apreensões do olhar anatômico?

\section{O nascimento da ilustração cientifica}

Das representações quiméricas de bonequinhos no interior de úteros fantásticos se chegará, no curso de três séculos, a representar o feto completamente separado do corpo materno, desenhado como se fosse um exemplar de uma nova espécie. Todavia, antes de analisar a ilustração científica oitocentista, na qual também muda profundamente o significado da representação do feto em âmbito médico-científico, pelo menos um parêntese se abre sobre as numerosas gravuras setecentistas que ilustram aquela que foi uma consistente, e absolutamente nova, produção editorial de textos de obstetrícia em língua vulgar na Europa e particularmente em italiano. ${ }^{44}$ Precursor na produção setecentista de manuais de obstetrícia prática em língua vulgar, isto é, também acessíveis a quem não conhecia o latim. E também na prática da obstetrícia, François Mauriceau, o mais famoso "cirurgião obstetra" francês, ilustrou o seu Des maladies des femmes grosses et accouchées, de $1668^{45}$, com uma série de figuras que depois serão apropriadas ou copiadas por muitos escritores de obstetrícia, como o italiano Orazio Valota, que no seu La levatrice moderna ainda as reproduz, mais de cem anos depois, em 1791. ${ }^{46}$ A série de pranchas que representam os fetos - dezesseis em Mauriceau, onze em Valota - citando apenas aquelas dos dois obstetras, representam as diversas posições em que podem ficar os bebês na hora do nascimento. ${ }^{47}$

43 Sobre o tema da relação entre o nível de conhecimento anatômico e representação artística, cf. também NUTTON, V. Representation and Memory in Renaissance Anatomical Illustration. In: MEROI, F.; POGLIANO, C. (Org.). Immagini per conoscere: dal Rinascimento alla rivoluzione scientifica, Atti della giornata di studio (Firenze, Palazzo Strozzi, 29 ottobre 1999). Florense: Olschki, 2001. p. 61-80.

44 Para a relação e a análise dos textos de obstetrícia setecentista, cf, PANCINO, C. Il bambino e l'acqua sporca, ..., p. 59-61, 224-225.

45 Editado em Paris.

46 VALOTA, O. La levatrice moderna: opera necessaria alle comari ed utile ai principianti d'ostetricia ed ai reverendi parrochi. Bergamo, 1791.

47 Não considero nessa contagem a prancha, muito conhecida, dos gêmeos, porque ela não faz parte da série de posições fetais. As onze representações dos fetos no útero de Valota foram retomadas daquelas, muito parecidas, de Mauriceau. As cinco posições "ausentes" são uma de ombros, uma de costas e três de barriga. Algumas dessas são extremamente fantasiosas e talvez esse seja o motivo da exclusão. 
O desenho, que se pretende explicativo, todavia ainda faz ecoar simplificações quinhentistas, e não é pouco o espaço que concede à fantasia. $\mathrm{O}$ útero é aberto graças ao tradicional artifício do corte da parte anterior, cujas pontas se abrem formando uma moldura quadrada dentro da qual surge o interior oval, o que permite a visão do feto. Naquele espaço oval, o bebê assume as diversas poses, que ainda assim lhe permitem ter espaço em volta de si, não está apertado, mas se encontra ali como em uma moldura de um pequeno quadro. $\mathrm{O}$ feto é na realidade um bebê bem formado, um "anjinho barroco" de idade indefinida, como aqueles de tantos desenhos seiscentistas e setecentistas. Dependendo da prancha, trata-se de crianças de alguns meses, às vezes de um ou dois anos, geralmente com cabelos. Enfim, como nos fetos das gravuras quinhentistas, em algumas os fetos estão de pé e às vezes estão com os olhos abertos, mas freqüentemente têm os olhos fechados e parecem dormir.

Então, as "criaturas" fantásticas dos textos quinhentistas tornaramse aqui anjinhos barrocos, crianças, ou pelo menos fetos bem formados. ${ }^{48}$

Uma grande prancha fora do texto do La levatrice moderna de Orazio Valuta ilustra o desenvolvimento do embrião/depois feto, e trata-se de algo novo no panorama das representações dos textos de obstetrícia. São sete figuras: de uma bolinha amorfa, na primeira figura, ao bebê completamente formado na sétima. O bebê, porém, é já uma "miniatura" na segunda figura. Estamos em 1791.

Deve-se recordar que anteriormente o teólogo Cangiamila, do qual já se falou rapidamente, havia inserido na sua Embriologia sacra (1745) uma prancha que ilustrava em dezessete imagens o desenvolvimento do feto. Ali, enquanto as figuras XVI e XVII, no final da série, apresentam bebês já formados bem desenhados e verossímeis, em posição que depois será dita "fetal", da figura I à figura VI as imagens ilustram a transformação de algo informe em algo formado.

Do esboço de cabeça e membros na figura VII, chega-se já, na figura XII, a um homúnculo em posição ereta que olha e quase sorri, e na figura $\mathrm{XV}$, grotescamente, "a criança" em pé brinca com o cordão e a placenta.

Ainda que, já há algum tempo, "a ciência médica e a experiência comum estivessem de acordo quanto ao reconhecimento de que o novo ser amadurecia e se aperfeiçoava progressivamente tomando uma forma

48 A propósito desse tipo de ilustração, cf. DUDEN, Il corpo della donna ..., op. cit., p. 42. 
humana bem definida"49, ainda por muito tempo as idéias sobre como tudo isso acontecia seriam muito confusas. Não demonstra saber muito sobre isso nem mesmo o teólogo palermitano, que deve ter tido possibilidade de fazer observação direta de fetos abortados. Nas ilustrações da Embriologia sacra aparece, além disso, a tentativa patética de fazer com que o feto assuma uma posição ereta (como acontecerão alguns decênios mais tarde, como já foi dito, com os esqueletos dos fetos da Encyclopédie).

Isso não deve surpreender, já que o principal objetivo da obra em que se encontram essas imagens é o de demonstrar a necessidade de batizar também os frutos da concepção em qualquer uma das fases do processo de formação, enquanto - alegava-se - dotados de humanidade e alma. ${ }^{50}$

No âmbito europeu, no século XVIII, são talvez Deventer, Roederer e Smellie os três maiores obstetras autores de tratados ilustrados com séries de pranchas, graficamente muito belas, e que serão freqüentemente retomadas por autores e ilustradores menores..$^{51}$ Todos os três obstetras citados inserem nos seus textos ilustrações de fetos no útero ao final da gestação (na verdade, eles são considerados os principais inspiradores dos modelos obstétricos em cera e em terracota).

Até o século XVIII o olhar médico se fixou aquém do ventre da mulher grávida, quase que respeitando o segredo que necessariamente envolve a gestação. Não é por acaso que durante muito tempo as pranchas que representam os bebês em formação os mostram freqüentemente em um útero que se abre ao olhar através de um corte que se parece com uma cortina. Foi assim com Mauriceau em 1681, e com Valota no final do século XVIII.

Foram médicos e cientistas - com as duas exceções, não por acaso, de um teólogo (Cangiamila) e de um naturalista (Scheuchzer) - que quiseram “olhar dentro" do ventre da mulher e que romperam com esse segredo. Os mesmos médicos e cientistas aos quais, todavia, parecia pouco importar a saúde das mães e dos nascituros. Na verdade pouco importava também aos Estados e à Igreja (a Igreja importava muito mais a alma do que a vida e a saúde ${ }^{52}$ ).

49 PROSPERI, Dare l'anima, op. cit., p. 253.

50 Sobre a Embriologia sacra de Cangiamila, cf. supra.

51 Hendrik van Deventer, Operationum chirurgicarum novum lumen exhibentium obstericantibus, qua fideliter manifestatur ars obstetricand, Lugduni Batavorum, 1733; Johann Georg Roederer, Elementi di ostetricia trdotti e corredati di figure in rame da Giuseppe Galletti, Firenze, Albizzini, 1795 (1758); William Smellie, A Treatise on the theory and practice of midwifery, to which is now added a set of anatomical plates, exhibiting the various cases that occur in practice... with explanations, London, Lister, 1754.

52 Mesmo quando alguns homens da Igreja aceitaram a possibilidade do aborto, como mal menor, a saúde da mulher foi a última das razões. (PROSPERI, Dare l'anima, op. cit., p. 241) 
O parto era coisa de mulher; os próprios médicos começaram a ocupar-se com os recém-nascidos muito tarde, a pediatria como especialidade e como interesse médico pela infância se delineará apenas no século XIX. Quando no século XVIII alguns membros do clero, com tanta insistência no olhar, quiseram olhar dentro do útero grávido da mulher, talvez não tenha sido apenas para batizar os fetos - como foi provavelmente para Cangiamila -, mas seguramente também, como declarava Scheuchzer, para conhecer e descrever as maravilhas da criação. Sobre a "ligação entre teologia e ciência médica sob a égide do Estado", fala Adriano Prosperi a propósito de Cangiamila, afirmando também que "os progressos da medicina tinham tornado possível um avanço sem precedentes no terreno da construção do ser humano". De fato, as "criaturas" no ventre "tinham se transformado em objeto de investimento altíssimo por parte dos saberes e poderes de todos os tipos" ${ }^{\prime \prime 3}$.

A concordância dos olhares de então começou a delinear uma história que se tornará cada vez mais complexa e intrincada. No âmbito científico, e ilustrativo, foram duas as obras que provocaram uma reviravolta na representação fetal: a Anatomia uteri gravidi, do médico escocês William Hunter, em 1774, e as Icones embryonum humanorum, do anatomista de Kassel, Samuel Thomas Soemmering, em 1799. $5{ }^{54}$ Basta dizer aqui que as ilustrações de ambos parecem ser dirigidas exclusivamente aos cientistas, e introduzem aquela que será a representação fetal científica oitocentista.

Finalmente, sobre as representações oitocentistas dos nascituros pode-se dizer que, mesmo nas suas variedades, elas podem ser tomadas como um conjunto que apresenta certa homogeneidade; algumas características comuns finalmente tornam essas imagens de fetos classificáveis dentro da "ilustração científica".

Por um lado, continua a produção de representações tipicamente didáticas nas quais, com maior precisão em relação ao passado, se mostram as posições do bebê no útero, no momento do nascimento. Vale lembrar que se trata quase sempre de "fetos bem formados", isto é, de bebês que

53 Cf. PROSPERI, Dare l'anima, ..., p. 216-217.

54 A respeito do valor das representações, podemos dizer que na ótica do nosso percurso de investigações Hunter aparece como o primeiro a oferecer uma interpretação fotográfica do feto no útero, o que significa uma reviravolta na história da representação fetal, enquanto Soemmering propõe, além de um modelo representativo, a primeira idéia "nova" de desenvolvimento embrionário e utiliza o sinal gráfico para oferecer uma interpretação visual de uma teoria da geração. 
estão para nascer. Outras imagens - e estas são de um tipo absolutamente novo - oferecem mais "informações" sobre a conformação e o aspecto do feto nos diversos estágios do desenvolvimento e, além disso, representam o feto "fora de contexto": abstraído do útero, do corpo, e da espera da mulher. A imagem é inserida em uma folha de papel em branco que se torna o seu novo contexto.

Já com Scheuchzer e Soemmering, e como será depois com os numerosos atlas de embriologia que serão editados a partir do século XIX, encontram-se sempre mais bebês em formação sem as mães. Essa abstração gráfica pode ser tomada como assinalando o momento de mudança da representação, antes excepcional, da criança abstraída do contexto materno.

Ainda deve-se ter presente que, como já nas ilustrações pioneiras de Hunter e Soemmering, no século XIX os fetos são desenhados com maior precisão graças aos conhecimentos anatômicos. A informação, como acontecerá com as tecnologias biomédicas do século XX, se transforma em signo, desenho, imagem. Trata-se, de toda forma, de um desenvolvimento do que foi dito quinhentos anos antes por Leonardo quando, proclamando a necessidade daquilo que Kemp chama "comunicação visual", perguntava "Oh, escritor, com quais letras escreverás com tamanha perfeição toda a figura, como faz aqui o desenho?"55

Deve-se lembrar que esse pensamento não teve lugar na iconografia quinhentista e seiscentista, quando se continuava a desenhar "criaturas", símbolos do que acontecia no progresso gerativo; agora o signo na prancha transmite informações sobre o interior do ventre grávido, mais precisas do que as palavras.

O símbolo - seja o bebezinho nos úteros-lâmpada ou o anjinho barroco de Mauriceau, Valota e tantos outros - cede lugar, por um lado, às informações traduzidas graficamente, e, por outro, à introdução de novos conteúdos não provenientes de informações, mas de expressões do pensamento, e traduzidos em formas gráficas que são ideológicas: em primeiro lugar, exatamente, o fundo branco em lugar das paredes do útero.

Compreender a historicidade dos diversos "contextos" - um fundo incolor, mais do que um útero - nos quais foram colocados em períodos sucessivos os desenhos dos fetos, ajuda a perceber uma mudança de significado e de função da própria representação.

55 KEMP, Il segno della verità ..., p. 67. 
Além disso, de novo e necessariamente, a informação torna-se mais precisa da mesma forma que em outros setores da medicina, valendo-se da observação de cadáveres (cadaverzinhos), sempre sob o estímulo do amor pelo estudo e pelo conhecimento.

Os artífices da representação no XIX, portanto, se modificaram e se refinaram: alguns desenhos são artisticamente muito bonitos. Ao contrário, de modo geral, o que distingue as imagens oitocentistas das suas precedentes é um sentimento de frieza: aquelas imagens de fetos normalmente suscitam arrepios naqueles que não estão acostumados com esse trabalho. Não obstante as discussões teológicas, já bastante difundidas, sobre a existência de alma no feto, freqüentemente naqueles desenhos os fetos parecem - como de fato são - desprovidos de sopro vital. Há, naquelas figuras, algo de monstruoso, em parte provavelmente devido ao fato de que a sua crescente correspondência aos vivos depende cada vez mais do estudo dos mortos, mas também porque se fala deles de modo não natural, mesmo através das imagens, sem fazer referência (gráfica) à mãe, que sozinha os mantém vivos.

Lazzaro Spallanzani não foi o único a colecionar cadáveres de fetos, que ainda hoje podem ser "admirados" 56 em sua coleção, como de resto os estudiosos de ciências médicas daquele tempo não desdenharam de se fazer retratar posando, em seus estúdios, com uma das mãos apoiada sobre um recipiente de vidro que - sobre a escrivaninha - continha um pequeno feto formado. ${ }^{57} \mathrm{E}$ tampouco isso perturbava as consciências e as preocupações pastorais dos clérigos.

Quanto à função das representações fetais oitocentistas, trata-se essencialmente de um papel que se desenvolve no interior da didática obstétrica dirigida aos médicos e às parteiras, mas também na esfera do conhecimento científico e erudito: como objeto de estudo e de reflexão dos eruditos, principalmente cientistas e médicos (mas também de literatos ${ }^{58}$, talvez de juristas, administradores e políticos, provavelmente clérigos). Por outro lado, para a maior parte da população, no inconsciente coletivo, o que acontece no ventre grávido de uma mulher ainda está envolto em mistério

56 Cf. a descrição da Collezione Spallanzani no site dos Museus Cívicos di Reggio Emilia - Palazzo dei Musei, disponível em: < http://musei.comune.re.it/Museo/museire.nsf $>$. Sobre a formação da coleção, cf. SPALLANZANI, M. F. La collezione naturalistica di Lazzaro Spallanzani: i modi e i tempi della sua formazione. Reggio Emilia: Tecnostampa, 1985.

57 ROEDERER, G. Elementa artis obstetriciae. Goettingen, 1759, p. de rosto.

58 Cf. D'YVOIRE, J. L'irruzione del feto nel mondo dell'immagine e dell'immaginario, op cit., p. 172-178. 
e, poderia se dizer, "tutelado pelo segredo". É necessário reforçar que ilustrações dos textos de obstetrícia e os atlas de embriologia, como também as pranchas que podiam ser exibidas nas aulas didáticas das faculdades de medicina, eram dirigidas a um público selecionado, certamente não a um grande público. Tratando-se, portanto, de desenhos de fetos para uso médico-científico-didático; as abstrações e os artifícios da representação encontram justificativa em sua utilização.

Todavia, a medicina não é apenas conhecimento e prática: sobretudo entre o século XVIII e o XIX, a medicina no Ocidente se define cada vez mais com um novo papel institucional e ideológico. De fato, torna-se sempre maior a influência do pensamento médico sobre cultura, imagens coletivas e finalmente sobre a opinião pública das sociedades ocidentais.

A partir do século XIX, de modo geral, o habitat dos fetos desenhados não é mais o útero, a simbiose materna, mas é um livro impresso ou um atlas, dos quais os fetos emergem para se tornar figuras autônomas do imaginário médico.

A figura tem o traço mais preciso, enquanto que a imagem ideal será levada a transferir-se da página para o imaginário, quase que se tornando uma espécie em si. Perdendo cada vez mais as conotações fantásticas, afetivas, familiares, se parecerá com um bebê somente no último estágio do seu desenvolvimento, isto é, quando a imagem de um feto completamente formado - em um fundo branco - é capaz de se sobrepor àquela de um recém-nascido visto pouco depois do parto.

Entidades separadas, os fetos da medicina permanecerão por muito tempo distantes das sensações que provêm da criança que uma mãe espera conhecer. Nos signos utilizados para a representação, nenhum vêm da mãe que espera.

É preciso salientar que aquela imagem científica do feto, pertencente até aquele momento histórico somente à medicina, começou a corresponder, de alguma forma, à nova realidade do médico à cabeceira das parturientes, isto é, de um membro e porta-voz da ciência médica na cena da gravidez e do parto. Não é por acaso que ao final de uma série de imagens de fetos no útero, em um famoso texto de obstetrícia, apareça finalmente aquela imagem do bebê recém-nascido nas mãos do médico. ${ }^{59}$ 


\section{Transmigração de imagens}

A partir de meados do século XVIII, mas mais ainda no século XIX, a imagem - e a idéia - de feto tenderá a transmigrar dos textos médicos para outros contextos culturais. Basta pensar nos desenhos de fetos em formação dos textos de "divulgação científica"; a imagem construída pela medicina deixará, então, o papel de objeto de estudo. Deixando a circunstância originária que a produziu, entrará em diversos territórios da cultura e, pouco a pouco, da mentalidade.

A imagem artificial construída com base em dados científicos e o nascituro no ventre materno começam a viver duas vidas paralelas. A existência do nascituro se desenvolve no segredo incognoscível; poderia se dizer que a "vida" da imagem se desenvolve primeiramente na folha em branco, para depois metaforicamente tomar corpo e se transferir para o imaginário científico, movendo-se como uma marionete guiada por fios invisíveis, conduzidos por personagens tecnicamente qualificados (de sexo masculino). $\mathrm{O}$ útero foi eliminado das representações e também qualquer referência ao corpo da mulher, ainda que esta fosse (seja) a "condição" única e necessária para a vitalidade do feto.

Paralelamente, em outros contextos do discurso, aquela "entidade autônoma" encontra-se com outras abstrações da especulação. Pode-se pensar no debate teológico sobre a existência da alma do feto que propõe a idéia - que certamente não era nova - de um pequeno ser humano, dotado de uma alma ${ }^{60}$, mas também ao espaço dedicado pelas várias áreas do pensamento político pelo populacionismo estatal aos "não nascidos", já depositários de projetos e de direitos (às vezes até contrastantes àqueles

60 Cf. BETTA, E. Ai limiti di una definizione: il "non-nato" tra medicina, religione e politica. Quaderni storici, 116, 2/2004. p. 587-603; L'âme et la vie: le Saint Office et l'obstétrique abortive. In: HERSCHKORN-BARNU, T. P. (Dir.). Faiseurs d'histoires et sujets d'histoires. Une nouvelle collaboration pour penser la médecine prénatale?,Actes des rencontres historiens de la naissancelobstétriciens des 16 e 17 mars 2000, Maternité des Bluets, Besins-Les Bluets, Paris 2000, p. 35-40. 
das mães).$^{61}$ Simplificando o amplo debate sobre a questão, pode-se dizer que os homens da Igreja - os quais contemplam os fetos desenhados nos textos médicos - debatem sobre a alma daquelas criaturas em formação, que crescem no escuro do ventre materno. Homens da lei e do Estado se perguntam se aqueles fetos desenhados (retratados a partir de mortos) não dão um rosto àquilo que não se vê, mas que é (na barriga das grávidas) titular de direitos, de heranças, talvez de propriedades e, sobretudo, de projetos úteis à sociedade (ou a uma parte da mesma).

A partir do momento em que a representação gráfica demonstra uma intenção cada vez maior de verossimilhança e visibilidade do feto, a figura que emerge disso é cada vez mais contrastante com a característica de obscuridade e de ocultação que, de outra parte, acompanha a existência do nascituro no ventre. Somente o parto, no estado "natural" da formação humana, sanciona a visibilidade e é o "gesto inaugural de toda a vida" já que somente depois do parto a criança é formada e não mais em formação, parida e não mais carregada. "Como revelam as expressões "trazer ao mundo' e 'dar à luz', o bebê vem de uma outra realidade, da escuridão protetora e vital ainda a ser descoberta, de um mundo diferente, do qual o parto constitui o limiar". ${ }^{63}$

Os fetos das imagens médicas aparecem, então, como fantasmas que tomaram forma a partir de uma presunção de conhecimento de vida, graças - já foi dito - ao estudo de cadáveres. E, que depois de terem assumido uma vida autônoma no imaginário - científico, teológico, jurídico - se tornaram paradoxalmente imagens a partir das quais se presume que se possam "conhecer" os bebês que ainda não viram a luz. Alguns artifícios da representação, tais como a separação do corpo materno no caso dos

61 Freqüentemente a "Felicidade Pública" foi vista no debate historiográfico como um projeto político repressivo. Por outro lado, como desse projeto fazia parte o grande programa estatal de tutela e garantia de bem-estar da população e, em sua base, projetos que se tornarão parte integrante de modelos de welfare adotados na segunda metade do XIX nas sociedades européias, foi um projeto, e uma utopia, de grande relevância social. Todavia, é irrefutável que uma das características de tal ideologia seja o deslocamento das fronteiras entre público e privado e o progressivo ingresso do Estado nos âmbitos da vida familiar e privada. Para uma reflexão recente sobre o tema, cf. PARMA, A. Alle origini della polizia medica: il progetto di Johann Peter Frank. In: PANCINO, C. (Org.). Politica e salute: dalla polizia medica all'igiene. Bologna: Clueb, 2003. p. 19-30.

62 VEGETTI FINZI, S. Volere un figlio, p. 6.

63 Ibid. p. 22; cf. também Hertz: "o nascimento produz para a consciência coletiva uma transformação igual aquela da morte, mas em sentido inverso: o indivíduo abandona o mundo invisível e misterioso até então habitado pela sua alma para entrar na comunidade dos vivos" (PROSPERI. Dare l'anima, op cit., p. 145). 
desenhos, a cor nas representações plásticas, a ausência de líquidos e secreções em ambos os casos, foram passagens necessárias para que o feto assumisse "vida própria".

Saber que há apenas 50 anos fetos mortos eram expostos em pequenos museus das escolas públicas dá a dimensão do quanto seja socialmente determinada a atribuição de características "pessoais ao feto", que certamente não são reconhecidas do mesmo modo por todas as sociedades e culturas (como também não o foram na história).

Aquelas imagens médicas dos nascituros, desenhadas para conhecer e compreender o mistério da verdade humana, como queria o anatomista bolonhês Giulio Cesare Aranzi, em 1564, foram também as matrizes de desenhos animados que talvez hoje impeçam as crianças de imaginar e fantasiar sobre as suas vidas no corpo da mãe. Ou então, encobrem as dúvidas essenciais sobre a misteriosa origem de cada um no ventre materno. A elaboração gráfica das imagens fetais e o refinamento de sua "precisão" cada vez maior por fim modificaram o nosso modo de pensar e de pensar sobre nós.

De qualquer forma, as ilustrações científicas e as imagens virtuais ou fotográficas dos fetos no útero perpetuam o perigoso engano de que a ciência (juntamente com a política e a religião) possa conhecer e dizer a última palavra sobre o que existe em nosso corpo, o que é o nosso corpo, o que nós somos. ${ }^{64}$

Séries de imagens, do século XVI ao XVIII, representaram o nascituro, ou melhor, a futura criança, como um pequenino ser escondido no ventre de sua mãe. É incrível perceber a semelhança dos desenhos "anatômicos" produzidos há séculos de distância. Textos fundadores de religiões e culturas ocidentais falam do escondido como característica da formação do ser humano. O salmo 139 afirma: "os meus ossos não te foram encober-

64 Atualmente existe a proposta de se poder "adotar" embriões. "O Comitê Nacional de Bioética vota um documento que solicita a adoção de embriões congelados para fazê-los nascer. Foi aprovado ontem, com apenas um voto contrário, o documento do Comitê Nacional de Bioética que pede a adoção dos embriões congelados e não utilizados pelos casais, com o objetivo de fazê-los nascer. $\mathrm{O}$ novo instituto, denominado Adozione per la nascita (APN), é fruto de uma reflexão rigorosa, que parte do princípio moral que equipara o embrião à pessoa humana desde a concepção" (SOLDANO, M. Adozione per la nascita: come ti cambio la legge 40, "il manifesto", 19 novembre 2005). Sobre o debate italiano e as referências legislativas, cf. ao menos SOLDANO, M. Genitori oggi con la procreazione assistita: Italia ed Europa a confronto: Tra politica, diritti, scienza e coscienza. Milano: Mediamed, 1999; e, da mesma autora, Un'appropriazione indebita: l'uso del corpo della donna nella nuova legge sulla procreazione assistita. Milano: Baldini Castoldi Dalai, 2004. 
tos, quando no oculto fui formado, e entretecido como nas profundezas da terra"65. "Criou-vos no ventre das vossas mães, criação após criação, em tríplice véu de trevas", diz o Corão $(39,6)$.

Quando esta pesquisa já estava terminada, em março de 2006, no ônibus, em Bolonha, eu ouvi esta conversa:
P.: É menino ou menina?
R.: Menino
P.: Como se chama?
R.: Matteo
P.: Quando nasce?

O véu de trevas e segredo há muito tempo foi rasgado, modificando de alguma forma o "vir" e o "ser" no mundo. ${ }^{66}$ 